\title{
TYK2 Variants in B-Acute Lymphoblastic Leukaemia
}

\author{
Edgar Turrubiartes-Martínez ${ }^{1,+, \pm(1)}$, Irene Bodega-Mayor ${ }^{1,+}$, Pablo Delgado-Wicke ${ }^{1,+}+\mathbb{C}$, \\ Francisca Molina-Jiménez ${ }^{1}$, Diana Casique-Aguirre ${ }^{2}{ }^{\circledR}$, Martín González-Andrade ${ }^{3}{ }^{\circledR}$, \\ Inmaculada Rapado ${ }^{4}$, Mireia Camós ${ }^{5}$, Cristina Díaz-de-Heredia ${ }^{6}{ }^{\circ}$, Eva Barragán ${ }^{7}$, \\ Manuel Ramírez-Orellana ${ }^{8}(0)$, Beatriz Aguado ${ }^{9}{ }^{\circledR}$, Ángela Figuera 9 , \\ Joaquín Martínez-López ${ }^{4,10,11(1)}$ and Elena Fernández-Ruiz $1,12, *(1)$
}

1 Molecular Biology Unit, University Hospital La Princesa and Research Institute (IIS-IP), Diego de León 62, 28006 Madrid, Spain; edgar.turrubiartes@uaslp.mx (E.T.-M.); irenebodega@gmail.com (I.B.-M.); pablodelwik@gmail.com (P.D.-W.); frmolina@gmail.com (F.M.-J.)

2 School of Medicine, Latin University of Mexico (ULM), Avenida San Jose 100, 38085 Celaya, Mexico; diana.casique@gmail.com

3 Biochemistry Department, Biosensors and Molecular Modelling Lab, Autonomous National University of México (UNAM), 04510 Mexico City, Mexico; martin@bq.unam.mx

4 Haematology Department, University Hospital 12 Octubre and Research Institute (i+12), Avenida de Córdoba s/n., 28041 Madrid, Spain; inmaculada.rapado@salud.madrid.org (I.R.); jmarti01@med.ucm.es (J.M.-L.)

5 Haematology Department, University Hospital Sant Joan de Déu and Research Institute (IRSJD), Passeig Sant Joan de Déu 2, 08950 Esplugues de Llobregat, Spain; mcamos@hsjdbcn.org

6 Paediatric Haematology and Oncology Department, University Hospital Vall d'Hebron and Research Institute (VHIR), Passeig de la Vall d'Hebron 119-129, 08035 Barcelona, Spain; crdiaz@vhebron.net

7 Molecular Biology Lab, Clinical Analysis Department, University and Polytechnic Hospital and IIS La Fe, Avenida de Fernando Abril Martorell 106, 46026 Valencia, Spain; barragan_eva@gva.es

8 Paediatric Haematology and Oncology Department, Paediatric University Hospital Niño Jesús (IIS-IP), Avenida de Menéndez Pelayo 65, 28009 Madrid, Spain; manuel.ramirez@salud.madrid.org

9 Haematology Department, University Hospital La Princesa (IIS-IP), 28006 Madrid, Spain; baguadobueno@gmail.com (B.A.); a.figueraalvarez@gmail.com (Á.F.)

10 Spanish National Cancer Research Centre (CNIO), 28029 Madrid, Spain

11 Faculty of Medicine, Complutense University of Madrid, 28040 Madrid, Spain

12 Faculty of Medicine, Autonomous University of Madrid, 28049 Madrid, Spain

* Correspondence: efruiz@salud.madrid.org; Tel.: +34-915202334

$\dagger$ These authors contributed equally to this work.

$\ddagger$ Current address: Research Centre for Health Sciences and Biomedicine, Autonomous University of San Luis Potosí, 78300 San Luis, Mexico.

Received: 5 October 2020; Accepted: 25 November 2020; Published: 28 November 2020

\begin{abstract}
B-cell precursor acute lymphoblastic leukaemia (B-ALL) is a malignancy of lymphoid progenitor cells with altered genes including the Janus kinase (JAK) gene family. Among them, tyrosine kinase 2 (TYK2) is involved in signal transduction of cytokines such as interferon (IFN) $\alpha / \beta$ through IFN $-\alpha / \beta$ receptor alpha chain (IFNAR1). To search for disease-associated TYK2 variants, bone marrow samples from 62 B-ALL patients at diagnosis were analysed by next-generation sequencing. TYK2 variants were found in 16 patients $(25.8 \%)$ : one patient had a novel mutation at the four-point-one, ezrin, radixin, moesin (FERM) domain (S431G) and two patients had the rare variants rs150601734 or rs55882956 (R425H or R832W). To functionally characterise them, they were generated by direct mutagenesis, cloned in expression vectors, and transfected in TYK2-deficient cells. Under high-IFN $\alpha$ doses, the three variants were competent to phosphorylate STAT1/2. While R425H and R832W induced STAT1/2-target genes measured by qPCR, S431G behaved as the kinase-dead form of the protein. None of these variants phosphorylated STAT3 in in vitro kinase assays. Molecular dynamics simulation showed that TYK2/IFNAR1 interaction is not affected by these variants. Finally, qPCR analysis revealed diminished expression of TYK2 in B-ALL patients at
\end{abstract}


diagnosis compared to that in healthy donors, further stressing the tumour immune surveillance role of TYK2.

Keywords: B-cell precursor acute lymphoblastic leukaemia; TYK2 variants; IFN $\alpha$; IFN $\alpha / \beta$ receptor alpha chain (IFNAR1); next-generation sequencing; molecular dynamics; TYK2 expression; immune surveillance

\section{Introduction}

B-cell precursor acute lymphoblastic leukaemia (B-ALL) is a neoplasia of lymphoid progenitor cells, characterised by large biological and clinical heterogeneity. Despite recent advances in genomic studies, there is still a limited understanding of the genetic basis of the disease [1,2]. B-ALL is the most frequent childhood cancer and accounts for $25 \%$ of adult acute leukaemia, remaining an important cause of morbidity [3]. Mutations in the non-receptor Janus kinase (JAK) 2 are important prognostic biomarkers in B-ALL [4,5], but the role of mutations in other members of this tyrosine kinase gene family is not well characterised.

JAK proteins have several domains that share seven homology regions (JH1-JH7) [6]. The carboxyl-terminal domain contains the active kinase domain (JH1) and the pseudokinase domain (JH2) that regulates catalytic activity. The N-terminal half of JAK proteins is most divergent and contains an src-homology 2 (SH2) domain (JH3 and part of JH4) with unknown function and a four-point-one, ezrin, radixin, moesin (FERM) homology domain (part of JH4 and JH5-JH7). The SH2 and FERM domains mediate cytokine receptor binding and regulate kinase activity. Tyrosine kinase 2 (TYK2) is a member of the JAK family involved in cytokine signal transduction in immune and haematopoietic cells $[7,8]$ and is able to associate to five different low-affinity cytokine receptor subunits, i.e., the interferon (IFN) $\alpha / \beta$ receptor alpha chain (IFNAR1), the interleukin (IL)- $12 R \beta 1$, the IL-10R $\beta$, the IL-6R $\alpha$, and the IL-13R $\alpha$, and collaborates with JAK1 or JAK2 transducing cytokine signals [9]. Activation of the JAK-cytokine receptor complex leads to the recruitment and JAK-mediated phosphorylation of the signal transducers and activators of transcription (STAT) family of transcription factors, whose subsequent dimerisation and nuclear translocation induces target gene expression [10].

TYK2 deficiency in humans is associated with increased susceptibility to bacterial and viral infection [11,12]. Altered IL-6 responses, hyper IgE syndrome and allergic asthma have also been described [13]. Loss of TYK2 in murine models results in reduced cytokine responses [14,15]. Moreover, Tyk2-null mice have increased predisposition to B lymphoid tumour formation due to an impaired immune surveillance [16]. Over the last years, several reports on the relationship between TYK2 and cancer have emerged, although its role is not clearly established $[17,18]$. In humans, fusion proteins containing TYK2 have been identified in patients with haematopoietic malignancies [18] and germline TYK2-activating mutations have been described in two cases of secondary B-ALL [19]. A TYK2 single-nucleotide polymorphism (SNP) in the kinase domain (P1104A) has been associated with different types of tumours [20] and has been found in about $7 \%$ of acute myeloid leukaemia (AML) patients [21]. TYK2 can also mediate drug resistance to the JAK2 inhibitor, ruxolitinib, via the formation of drug-resistant TYK2/JAK2 heterodimers [22]. Given the importance of a fully functional immune response for appropriate tumour surveillance, and that those immune responses rely on JAK-dependent signal transduction, it is of high relevance to elucidate the role of the interaction of cytokine receptors, JAK proteins, and their target genes. In this context, the search and functional characterisation of TYK2 variants could clarify their relevance in disease development and/or progression.

In this study, we analysed bone marrow samples from 62 B-ALL patients at diagnosis by next-generation sequencing (NGS), searching for disease-associated TYK2 variants. We found a novel variant, TYK2 S431G, together with the rare polymorphisms TYK2 R425H (rs150601734) and TYK2 R832W (rs144995884). The present study describes a functional characterisation of these variants, 
finding differences in their kinase activity and IFN $\alpha$-mediated signalling. Additionally, we found a diminished TYK2 expression in B-ALL patients compared to healthy donors. Taking together these results, we propose a role of TYK2 in the pathogenesis of B-ALL through the alteration of IFN $\alpha$ signalling.

\section{Material and Methods}

\subsection{Patients and Data Collection}

A total of 88 B-ALL patients referred from six Spanish centres to the Molecular Biology Unit at La Princesa University Hospital, Spain, between January 2013 and December 2015 were eligible for this study. Sixty-seven patients were children $(76.14 \%,<18$ years) and 21 were adults $(23.86 \%,>18$ years). The diagnosis of B-ALL was based on morphological, immunophenotypic, and genetic features of leukaemic blast cells, as described previously [23].

\subsection{Ethics Statement}

Written informed consent was obtained from each patient or from legal guardians before patients entered the study in all hospitals involved. The study was approved by the Clinical Research Ethics Committee of La Princesa University Hospital (approval ID: PI-655) on 7 November 2012.

\subsection{DNA Isolation and Next-Generation Sequencing Assay (NGS)}

Amplicon-based NGS was performed on 62 samples obtained from untreated patients at diagnosis (54 patients were children $(87.10 \%,<18$ years) and eight were adults $(12.90 \%,>18$ years) and five B-cell lines (Granta-519 and Jeko1: leukaemic transformation of mantle cell lymphoma (MCL); Ramos: Burkitt's lymphoma; Mino: MCL and REH: B-ALL) from ATCC. Genomic DNA was extracted from bone marrow samples with the MagNA Pure LC DNA Isolation Kit (Roche Diagnostics, Basel, Switzerland) following the manufacturer's instructions. An amplicon-based NGS assay was performed with 45 amplicons ranging from 275 to $144 \mathrm{bp}$ (AmpliSeq; ThermoFisher Scientific, Waltham, MA, USA) covering the exon and flanking intron regions of TYK2 (RefSeq: NM_003331.4) with an overall coverage of 93.98\%, using the Ion Torrent Sequencing Platform (Applied Biosystems, Cheshire, UK) (Table S1). Data were validated by Sanger using TaqMan ${ }^{\circledR}$ SNP Genotyping Assays (Applied Biosystems) or PGM Sequencing Platform (Applied Biosystem, Cheshire, UK). Amplicon library pooling, purification, emulsion PCR, sequencing, validation of variants, data processing, and analysis was performed as previously described [5]. The novel variant S431G was annotated in GeneBank (BankIt2289375 ENST00000525621.6 MN842724).

\subsection{Site-Direct Mutagenesis, Plasmids, Cell Culture, and Transfection}

TYK2 variants were obtained by oligonucleotide-mediated site-direct mutagenesis (ThermoFisher Scientific) of wild-type TYK2 cloned in the pRc-CMV-neo eukaryotic expression vector (pRc-Tyk2) provided by Dr. Pellegrini (Institut Pasteur, Paris, France) [7] and the final constructs were sequenced. The control variants pRc-TYK2 K930R (kinase dead) and pRc-TYK2 V678F (catalytically hyperactive) were also provided by Dr. Pellegrini, together with the 293T and TYK2-deficient, IFN $\alpha$-unresponsive human fibrosarcoma 11,1 cells (also called U1A) [7]. The recessive mutant 11,1 (U1A) was obtained from the parental 2fTGH cell line, derived by genetic approach to isolate regulatory mutations in the IFN $\alpha$ signalling pathway [24]. Mycoplasma free 293T and U1A cells were grown in Dulbecco's modified Eagle medium (DMEM) (Gibco; ThermoFisher Scientific) containing 10\% heat-inactivated foetal calf serum (FCS). Transfection of pRc-TYK2 mutants was performed with FuGENE6 (Roche Applied Science, Penzberg, Germany) following the manufacturer's instructions. Final, stable TYK2-expressing clones were selected in $400 \mu \mathrm{g} / \mathrm{mL}$ of Geneticin G418, and resistant colonies were ring-cloned two weeks later and expanded. 


\subsection{Western Blot and Immunoprecipitation Analysis}

Cells were starved for $2 \mathrm{~h}$ in serum-free DMEM before IFN $\alpha-2 b$ stimulation for 15 min with concentrations ranging from 10 to 500 pM (Immunotools GmbH; Friesoythe, Germany). Cells were lysed in RIPA buffer using a protease and phosphatase inhibitor cocktail (ThermoFisher Scientific). Protein content was determined by a BCA Protein Assay Kit (ThermoFisher Scientific), and $30 \mu \mathrm{g}$ was separated by 7\% SDS-PAGE, analysed by Western blot and revealed using ECL detection reagents (ThermoFisher Scientific). For re-probing, blots were stripped with Restore plus Western blot stripping buffer (Cultek, Madrid, Spain) for $10 \mathrm{~min}$ at room temperature. The following Abs were used: anti phospho (p)-STAT1 (Y701), anti pSTAT2 (Y690), anti p-STAT3 (Y705), anti p-TYK2 (YY1054/55), directed to the activation loop tyrosine (Cell Signalling Technology, Beverly, CA, USA), anti TYK2 mAb T10-2 (Hybridolab, Institut Pasteur, kindly gifted by Dr. S. Pellegrini) raised against a GST fusion protein containing amino acids 289-451 of human TYK2, anti STAT3 (Santa Cruz Biotechnology Inc., Santa Cruz, CA, USA) and anti Tubulin (Sigma-Aldrich, St. Louis, MO, USA).

\subsection{In Vitro Kinase Assay}

An in vitro kinase assay was performed as described [25]. Briefly, cells were lysed in $50 \mathrm{mM}$ Tris (pH 6.8), 0.5\% Nonidet P-40, $200 \mathrm{mM} \mathrm{NaCl}, 10 \%$ glycerol, and $1 \mathrm{mM}$ EDTA in presence of protease inhibitors. TYK2 was immunoprecipitated from $2 \mathrm{mg}$ lysate using non-commercial R5-9 polyclonal $\mathrm{Ab}$ (a gift from S. Pellegrini, Institut Pasteur, Paris, France) and $40 \mu \mathrm{L}$ protein A/G PLUS-Agarose (Santa Cruz Biotechnology, Inc.) with slow rotation at $4{ }^{\circ} \mathrm{C}$ overnight. Immunocomplexes were washed three times in buffer 1 ( $50 \mathrm{mM}$ Tris ( $\mathrm{pH}$ 6.8), $400 \mathrm{mM} \mathrm{NaCl}, 0.5 \%$ Triton X-100, and $1 \mathrm{mM}$ EDTA), once in buffer 2 (50 mM Tris ( $\mathrm{pH} 6.8$ ) and $200 \mathrm{mM} \mathrm{NaCl}$ ), and once in kinase buffer (50 mM HEPES (pH 7.6) and $10 \mathrm{mM} \mathrm{MgCl}_{2}$ ). The kinase reaction was carried out in kinase buffer, in the presence of $0.06 \mu \mathrm{g}$ of recombinant (r) STAT3 (SignalChem Lifesciences Corporation, British Columbia, Canada), and with or without $30 \mu \mathrm{M}$ ATP at $30^{\circ} \mathrm{C}$ for $5 \mathrm{~min}$ in a total volume of $30 \mu \mathrm{L}$. The reaction was finished by boiling in Laemmli buffer. Half of the sample was loaded for SDS-PAGE and transferred to a nitrocellulose membrane, and phosphorylated products were analysed by Western blotting.

\subsection{Expression Analysis}

For TYK2 expression analysis, 88 B-ALL patients were compared to 105 healthy donors. Reverse-transcriptase polymerase chain reaction (RT-PCR) was performed using Superscript R Vilo TM cDNA kit (Applied Biosystems) with $1 \mu \mathrm{g}$ total RNA isolated from peripheral blood mononuclear cells (PBMCs), isolated by Ficoll from $10 \mathrm{~mL}$ of peripheral blood, in the case of healthy donors, or bone marrow at diagnosis, in the case of patients, using Ultraspec (Biotecx, Houston, TX, USA). Complementary DNA (cDNA) samples were diluted 1:10 before amplification by qPCR using TaqMan Fast-Advanced MMix (Applied Biosystems) in a CFX384 Real-Time System (Roche Diagnostics). The following TaqMan assays were used: Hs00177464_m1 (TYK2), Hs03929097_g1 (GAPDH) (ThermoFisher Scientific) following the manufacturer's protocols. For each sample, relative mRNA levels were determined using the comparative $\mathrm{Ct}(\triangle \Delta \mathrm{Ct})$ method (normalised to GAPDH). In the case of U1A transfected cells, different clones were incubated 1 and $3 \mathrm{~h}$ with $500 \mathrm{pM}$ of IFN after $2 \mathrm{~h}$ of serum starvation, and total RNA isolation and RT-PCR were performed as detailed above. TaqMan assays used were Hs00971965_m1 for interferon regulatory factor 1 (IRF1), Hs00973635_m1 for 2'-5'-oligoadenylate synthetase 1 (OAS1), Hs02330328_s1 for suppressor of cytokine signalling 3 (SOCS3), and Hs01065498_m1 for serine/threonine-protein kinase Pim-1 (PIM1) (ThermoFisher Scientific).

\subsection{Structural Analysis of R425H and S431G TYK2 Variants Interacting with IFNAR1 and Molecular Dynamics Analysis}

The crystallographic data of human TYK2 and the structural complexes were obtained from the Protein Data Bank (PDB ID: 4PO6). Visualization, structural analysis of the protein and the "in silico" 
mutant were made with PyMOL [26]. The TYK2 wild type (WT)-IFNAR1, TYK2 R245H-IFNAR1, and TYK2 S431G-IFNAR1 complexes were verified, cleaned, and ordered with the pdb4amber scrip before starting the preparation in order to generate suitable topologies from the LEaP module of AMBER $19[27,28]$. Each structure and complex was subjected to the following protocol: hydrogen's and other missing atoms were added using the LEaP module with the leaprc.protein.ff19SB parameter set, $\mathrm{Cl}^{-}$or $\mathrm{K}^{+}$counterions were added to neutralise the system, the complexes were then solvated in an octahedral box of explicit TIP3P model water molecules localising the box limits at $12 \AA$ from the protein surface. All calculations were made using graphics processing unit (GPU)-accelerated molecular dynamic (MD) engine in AMBER (pmemd.cuda) [29]. The protocol consisted in performing a minimisation of the initial structure, followed by 50 ps heating and pressure equilibration at $315 \mathrm{~K}$ and $1.0 \mathrm{~atm}$ pressure, respectively. Finally, the system was equilibrated with 500 ps before starting the production of MD, which consisted of $50 \mathrm{~ns}$ for each complex. Frames were saved at $10 \mathrm{ps}$ intervals for subsequent analysis. All analyses were done using CPPTRAJ [30] and binding free energies calculated by molecular mechanics/Poisson-Boltzmann surface area (MM/PBSA) [31]. The calculations of root mean square deviation (RMSD) and root mean square fluctuation (RMSF) were made, considering C, $\mathrm{CA}$, and $\mathrm{N}$ atoms.

\subsection{Statistical Analysis}

When analysing STAT target genes' expression, cell line intrinsic differences between time conditions were analysed by two-way ANOVA, performing post hoc Bonferroni tests for intergroup differences (* vs. $0 \mathrm{~h}$ from each TYK2 variant; \# vs. wild type (WT)'s same time condition. For * and \#: $\left.{ }^{*} p<0.05 ;{ }^{* *} p<0.01 ; * * * p<0.001 ;{ }^{* * * *} p<0.0001\right)$. Differences in TYK2 expression between healthy controls and B-ALL patients were evaluated using the Mann-Whitney U test. Association between TYK2 expression and patient age was estimated using Spearman correlation $(\rho)$. Prior to the correlation analysis, the Shapiro-Wilk test was performed. Overall survival (OS) curves were estimated by the Kaplan-Meier method, and the log-rank test or Tarone-Ware test. Overall survival risk by group was estimated using Cox regression. The $\chi^{2}$ and Fisher's exact two-sided tests were used for comparisons between categorical variables, and the Wilcoxon rank sum test or $t$ test was used for continuous variables. $p$-values $<0.05$ were considered significant. The statistical analysis was carried out with SPSS program (Statistical Package for Social Sciences Inc., Chicago, IL, USA; version 22.0) and the version 6.05 of the program GraphPad Prism (GraphPad Software Inc, San Diego, CA, USA), also used for graphical representation.

\section{Results}

\subsection{TYK2 Non-Synonymous Variants Found in B-ALL Patients}

We performed ultra-deep sequencing of bone marrow samples at diagnosis from 62 B-ALL patients and five B-cell lines (Granta-519, Jeko1, Ramos, Mino, and REH). The blast count in the patients ranged from $50 \%$ to $96 \%$ with a median of $90 \%$. We found $T Y K 2$ non-synonymous variants in 16 patients $(25.8 \%)$ (Table S2). One of them had a non-described substitution (Table 1). TYK2 variants were not associated with survival or any main clinical characteristic of patients, including genetic abnormalities (data not shown). None of the TYK2 variants were found in the five B-cell lines analysed, whereas seven were detected in B-ALL samples: located in exon 9 (JH4), rs150601734 that causes arginine-to-histidine substitution (p.Arg425His) (TYK2 R425H) in one patient; in exon 15 (JH2), rs12720356 (p.Ile684Ser) (TYK2 I684S) in eleven patients (17.74\%), and rs55882956 (p.Arg703Trp) (TYK2 R703W) in one case; in exon 18 (JH2), rs144995884 (p.Arg832Trp) (TYK2 R832W) was detected in one patient. 
Table 1. Disease-associated non-synonymous TYK2 variants.

\begin{tabular}{|c|c|c|c|c|c|c|c|}
\hline rs & $\begin{array}{c}\text { Ancestral > } \\
\text { Derived }^{\text {a }}\end{array}$ & $\begin{array}{l}\text { Location } \\
\text { (Chr) }\end{array}$ & EUR MAF ${ }^{b}$ & $\begin{array}{l}\text { Protein Change } \\
\text { (Domain) }\end{array}$ & $\begin{array}{l}\text { Number of } \\
\text { Patients }\end{array}$ & Disease Association & Ref. \\
\hline 150601734 & $\mathrm{G}>\mathrm{A}$ & 19:10364707 & $0.000008(\mathrm{~A})^{\mathrm{c}}$ & p.R425H (FERM) & 1 & T-ALL cell line & [32] \\
\hline- & $A>G$ & 19:10364724 & - & p.S431G (FERM) & 1 & - & \\
\hline 12720356 & $A>C$ & 19:10359299 & $0.092(\mathrm{C})$ & $\begin{array}{c}\text { p.I684S } \\
\text { (pseudokinase) }\end{array}$ & 11 & $\begin{array}{l}\text { Protects against RA } \\
\text { and autoimmunity; } \\
\text { AML, T-ALL cell line }\end{array}$ & {$[21,32,33]$} \\
\hline 55882956 & $\mathrm{G}>\mathrm{A}$ & 19:10359243 & $0.001(\mathrm{~A})$ & $\begin{array}{c}\text { p.R703W } \\
\text { (pseudokinase) }\end{array}$ & 1 & AML & [21] \\
\hline 144995884 & $\mathrm{G}>\mathrm{A}$ & 19:10356691 & $0.0(\mathrm{~A})$ & $\begin{array}{c}\text { p.R832W } \\
\text { (pseudokinase) }\end{array}$ & 1 & - & \\
\hline 34536443 & $G>C$ & 19:10352442 & $0.029(\mathrm{C})$ & p.P1104A (kinase) & $2^{d}$ & $\begin{array}{c}\text { Decreased } \\
\text { susceptibility to RA } \\
\text { and autoimmunity } \\
\text { Susceptibility to } \\
\text { mycobacteria } \\
\text { NF1-PNSTs and } \\
\text { tumour tissues }\end{array}$ & {$[20,34-38]$} \\
\hline 55886939 & $\mathrm{~T}>\mathrm{C}$ & 19:10350910 & $0.004(\mathrm{C})$ & p.E1163G (kinase) & 1 & T-ALL cell line & [32] \\
\hline
\end{tabular}

Two patients bearing rs12720356 (p.Ile684Ser) (TYK2 I684S) also had rs34536443 (p.Pro1104Ala) (TYK2 P1104A), located in exon 23 (JH1). Finally, one patient showed rs55886939 (p.Glu1163Gly) (TYK2 E1163G) in exon 25. In addition to these SNPs, we found a novel variant located in exon 9, which results in the replacement of serine by glycine (p.S431G) (TYK2 S431G) in one patient. This variant is localised in the FERM domain (JH4) of the protein and has not been previously described.

The variant allele frequency (VAF) obtained for the total variants analysed ranged from $32 \%$ to $54 \%$ with a median of $49 \%$ (Table S2).

\subsection{TYK2 Variants Present Differences in IFN Signalling Response and in STAT-Target Genes Induction}

We decided to evaluate the effect in protein function of the novel variant TYK2 S431G, the very rare TYK2 R425H and TYK2 R832W that were not characterised previously (Figure 1).

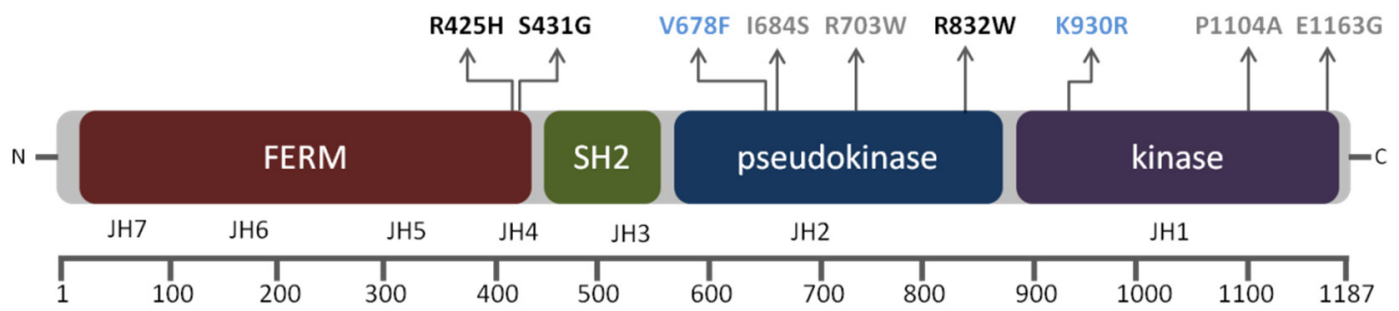

Figure 1. Schematic representation of structural and functional domains of tyrosine kinase 2 (TYK2) protein with the non-synonymous variants detected in this study (functional characterised variants in black; artificial mutant controls in blue: kinase-dead form of the protein (TYK2 K930R) and the catalytically hyperactive form (TYK2 V678F). Boxes illustrate functional domains from $\mathrm{N}$ - to C-terminus and the corresponding Janus kinase (JAK) structural homology domains (JH1-JH7) are marked below. Amino acid numbers are shown in the lower bar scale according to the human TYK2 protein sequence (RefSeq: NM_003331.4; FERM domain: 26-431, SH2 domain: 452-551, pseudokinase domain: 551-875, and kinase domain: 897-1176).

For this purpose wild-type (WT) TYK2 and the three engineered TYK2 mutant cDNAs were cloned in the pRc/CMV-neo expression vector, as well as the kinase-dead form of the protein (TYK2 $\mathrm{K} 930 \mathrm{R}$ ) as a negative control, and the catalytically hyperactive form (TYK2 V678F) as a positive control [39]. First, we decided to compare the basal auto-phosphorylation activity of TYK2 variants 
by expressing them in 293 T cells (Figure S1A). Cell lysates were analysed by Western blot using the phospho-specific antibody directed to the activation-loop tyrosines (Tyr 1054-1055). TYK2 WT and the catalytically hyperactive TYK2 V678F were phosphorylated on tyrosine and activated STAT3. However, neither the catalytically inactive form of the protein (TYK2 K930R) nor the three variants (TYK2 R425H, TYK2 S431G, and TYK2 R832W) were auto-phosphorylated or able to activate STAT3. Then, the TYK2 variants were stably transfected in human TYK2-deficient U1A cells to test their phosphorylation state and signal capacity in response to IFN $\alpha$. Cell clones were selected based on their TYK2 expression evaluated by Western blot (Figure S1B). The expression levels of the variants except K930R, were lower than those in WT. These cell clones were exposed for 15 min to increasing concentrations of IFN $\alpha$ to compare their phosphorylation state by Western blot (Figure 2). As expected, TYK2, STAT1, STAT2, and STAT3 were phosphorylated in response to IFN $\alpha$ in TYK2 WT and TYK2 V678F-transfected cells, whereas they remained non-phosphorylated in cells transfected with TYK2 K930R. TYK2 R425H and TYK2 R832W were able to mediate STAT2 phosphorylation in response to increasing doses of IFN $\alpha$, but STAT1 became phosphorylated only at the highest dose of the cytokine (500 pM). On the other hand, TYK2 S431G only presented STAT1 and STAT2 phosphorylation at 500 pM of IFN $\alpha$. Therefore, we concluded that these changes in the FERM and JH2 domains of TYK2 impaired both its ability to phosphorylate STAT3 and the activation of STAT1 in response to low and moderate doses of the cytokine.

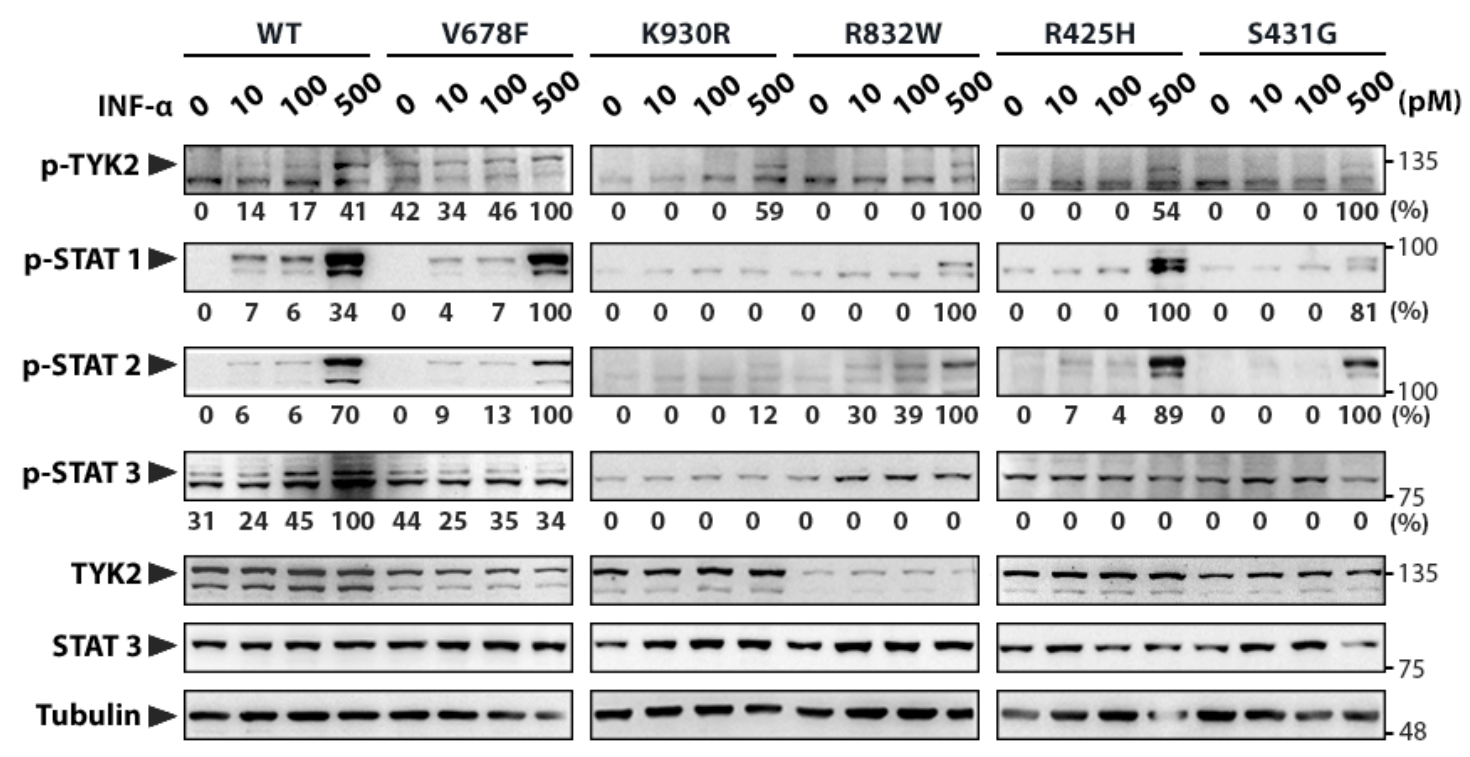

Figure 2. Functional analyses of TYK2 variants. Human TYK2-deficient U1A cell line was transfected with the different TYK2 variants and clones stably expressing these variants were selected. Clones were stimulated with the indicated doses of IFN $\alpha$ for $15 \mathrm{~min}$, and the level of phosphorylation of TYK2 variants and STAT1-3 transcription factors was assessed by Western blot. Arrowheads point out the size of specific proteins and molecular weight markers $(\mathrm{kDa})$ are noted on the right. Quantification of phosphorylated proteins is relative to TYK2 total protein (to account for TYK2 expression differences among cell lines) and then to Tubulin (shown under each lane/membrane). Values are expressed as percentage of the highest value of each membrane. WT: wild-type TYK2; V678F: catalytically hyperactive TYK2; K930R: kinase-dead TYK2 (ATP-binding site mutant); R832W, R425H, and S431G: disease-associated TYK2 variants. A representative result of three independent experiments is shown (Figure S2).

To gain further insight into STAT biological activity in U1A cell clones under IFN $\alpha$ stimulation, we assessed the induction of IFN $\alpha$-stimulated early genes after treating them for different times with 500 pM IFN $\alpha$. Transcripts of IRF1, a STAT1-dependent gene; OAS1, a STAT1- and STAT2-dependent gene; and SOCS3 and PIM1, both STAT3- and STAT5-dependent genes [39-42] were quantified by qPCR (Figure 3). TYK2 V678F cells treated with IFN $\alpha$ for 3h showed 4- and 27-fold induction of IRF1 and 
OAS1 transcripts, respectively, compared to untreated cells; whereas TYK2 WT showed half induction of both genes compared with the catalytically hyperactive variant. Surprisingly, considering IRF1 induction, the TYK2 R832W expressing clone reached earlier a similar level to that showed by TYK2 V678F, whereas TYK2 R425H was comparable to TYK2 WT. In the case of OAS1, TYK2 R832W induced the gene in a similar way to the WT at $3 \mathrm{~h}$, but the rest of the variants showed a significantly diminished induction after the same time of IFN $\alpha$ stimulation. In addition, significant induction was also observed after $1 \mathrm{~h}$ by both TYK2 V678F and TYK2 R832W. On the other hand, TYK2 S431G behaved as the kinase-dead TYK2 K930R for both genes. SOCS3 and PIM1 were not consistently induced at the times selected by any of the TYK2 variants with the exception of R832W, which reached a significant induction of SOCS3 after $1 \mathrm{~h}$ of IFN $\alpha$ stimulation. This result further supports the finding that TYK2 R832W confers higher susceptibility to IFN $\alpha$, whereas TYK2 S431G cells remain unable to appropriately respond to this cytokine.

IRFI

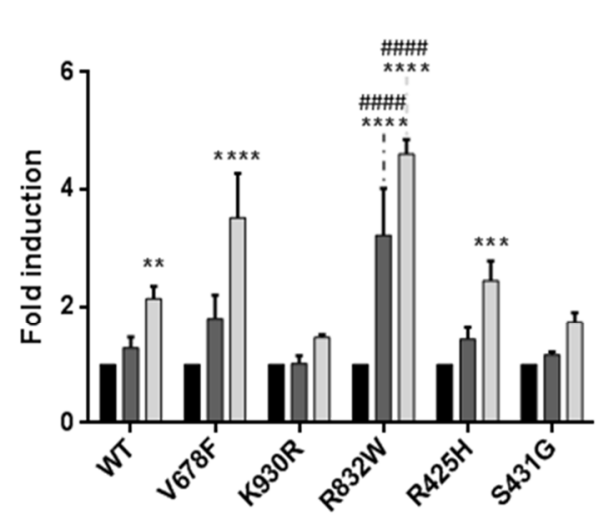

$\operatorname{socs} 3$

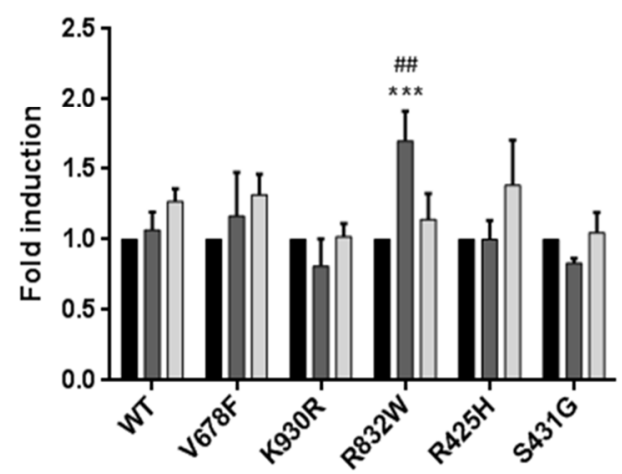

OAS1
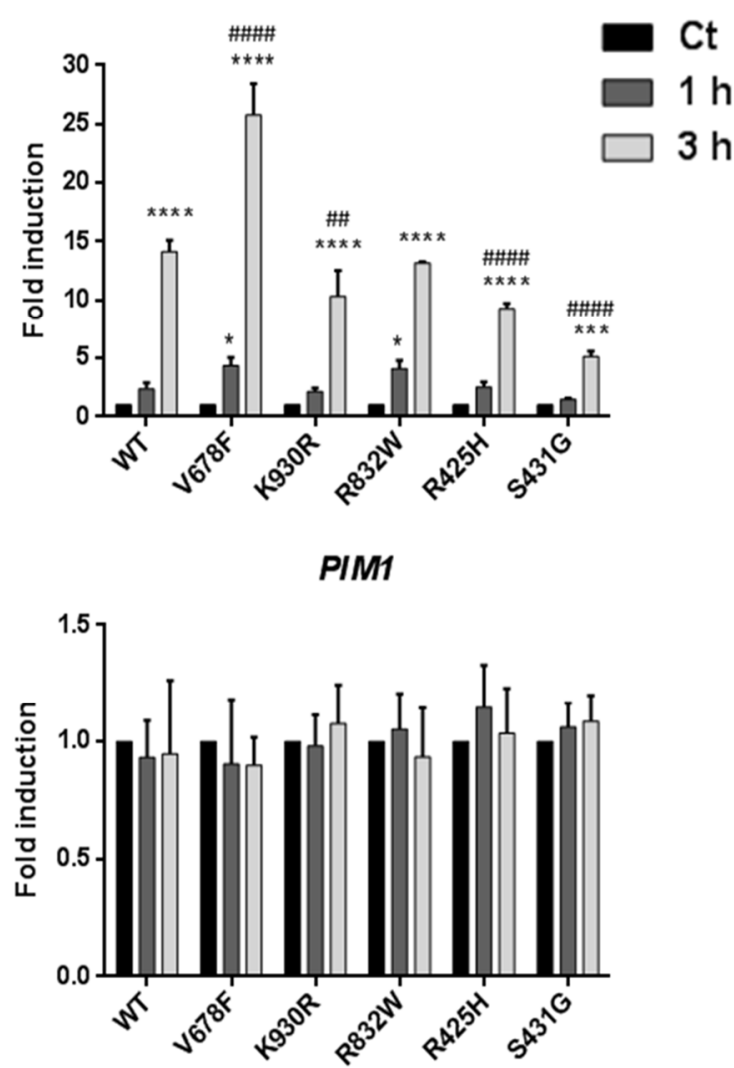

Figure 3. STAT-target gene expression induced by IFN $\alpha$ in U1A cells expressing TYK2 variants. Cells were treated with $500 \mathrm{pM}$ IFN $\alpha$. Total RNA was extracted, reverse-transcribed, and analysed by RT-qPCR for the indicated genes. Values were normalised to GAPDH and are expressed as $n$-fold versus untreated cells for each variant. Mean values of three independent experiments \pm SD are shown. Two-way ANOVA was used for statistical analysis, performing post hoc Bonferroni tests for intergroup differences. * For each variant, comparison between the indicated time and untreated cells; \# for each time condition, comparison between each variant and WT. For ${ }^{*}$ and $\#:{ }^{*} p<0.05 ;{ }^{* *} p<0.01$; *** $p<0.001 ;{ }^{* * * *} p<0.0001$.

\subsection{In Vitro Kinase Activity of TYK2 Variants Is Impaired}

To further confirm STAT response when stimulating these TYK2 variants, we first compared the auto-phosphorylation ability of one of the FERM domain variants (TYK2 S431G) and the TYK2 $\mathrm{R} 832 \mathrm{~W}$, localised at the pseudokinase domain, with that of TYK2 WT. To this end, the protein was immunoprecipitated with anti-TYK2 T10-2 mAb from cell lysates of each U1A cell clone and subjected 
to an in vitro kinase assay in the presence or absence of added ATP (Figure 4). Recombinant STAT3 (rSTAT3) was added to the reaction as exogenous substrate. The reaction product was analysed by immunoblotting with anti p-TYK2 and anti p-STAT3 Abs. In intact cells in the absence of ATP, no phosphorylation was detected in any of the assays, but when ATP was added to the reaction, p-TYK2 and p-STAT3 were detected in TYK2 WT reaction, whereas no signal was detected in the assays with TYK2 S431G or in the TYK2 R832W. When U1A cell clones were previously stimulated with IFN $\alpha$, an increase in p-TYK2 was observed in TYK2 WT but not in TYK2 S431G or TYK2 R832W (Figure 4, right panel). Taken together, these data indicate that, in vitro, TYK2 S431G and TYK2 R832W have impaired basal and IFN $\alpha$-induced auto-phosphorylation activity and are also unable to activate STAT3. Therefore, replacements of Ser431 by Gly in the FERM domain and Arg832 by Trp in the JH2 domain suppress TYK2 kinase activity.

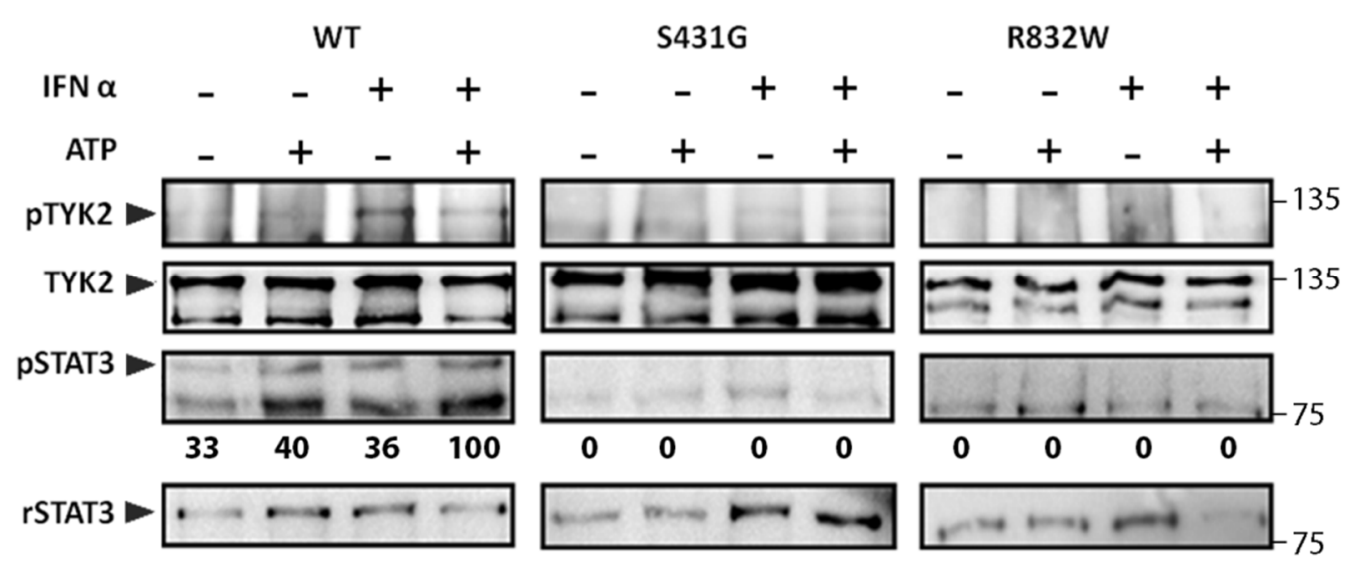

Figure 4. In vitro kinase activity of TYK2 WT, TYK2 S431G, and TYK2 R832W proteins. TYK2 was immunoprecipitated with anti-TYK2 Ab from non-stimulated cells or cells stimulated with IFN $\alpha$ $(500 \mathrm{pM})$ for $15 \mathrm{~min}$ and subjected to in vitro kinase reaction in the presence or absence of $30 \mu \mathrm{M}$ ATP for $5 \mathrm{~min}$ at $30{ }^{\circ} \mathrm{C}$. Recombinant STAT3 (rSTAT3) was added to the reaction as exogenous substrate. The phosphorylation level of the indicated proteins was analysed by immunoblotting. STAT3 phosphorylation was represented relative to rSTAT3 and then to TYK2, to account for differences in the amount of immunoprecipitated TYK2 in each sample. Values are expressed as percentage of the highest value of each membrane. A representative result of three independent experiments is shown.

\subsection{Molecular Dynamics of the TYK2 R425H- and S431G-IFNAR1 Complex Interaction}

The FERM domain is involved in the scaffold formed by TYK2 together with IFNAR1, leading to an appropriate downstream signalling of the receptor complex [43]. However, according to the crystallographic structure of TYK2 interacting with IFNAR1 [44], this receptor mostly binds to the SH2 domain and the F1 and F2 subdomains of FERM (Figure 5A). The region where R425H and S431G mutations are located in the F3 subdomain of FERM domain is very distant from the binding site of IFNAR1, thus decreasing the likelihood that those point-mutations may affect the interaction of TYK2 with IFNAR. To confirm this point, the impact of S431G and R425H mutants on this protein interaction was determined by molecular dynamics (MD) analysis of the TYK2-IFNAR1 complex using the WT, the $\mathrm{R} 425 \mathrm{H}$ and the S431G mutants (Figure 5B,C). Regarding the R832W mutant, it was not included in the MD studies, since it is found in the pseudokinase domain at $82.2 \AA$ from the protein-peptide interaction under study (Figure S3). 


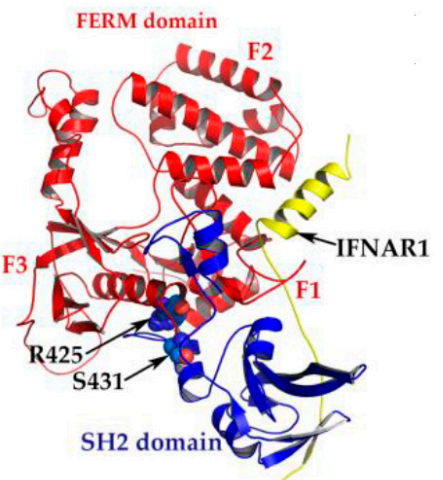

(A)

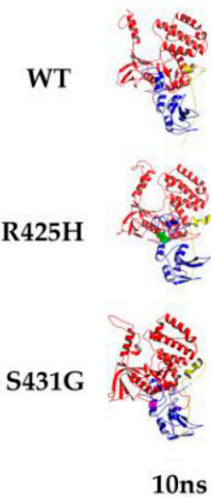

10ns
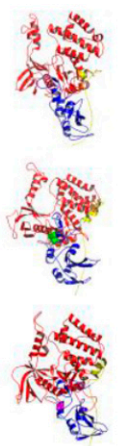

20ns
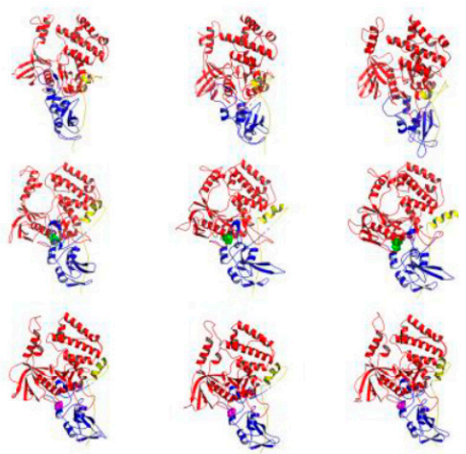

30ns

(B)

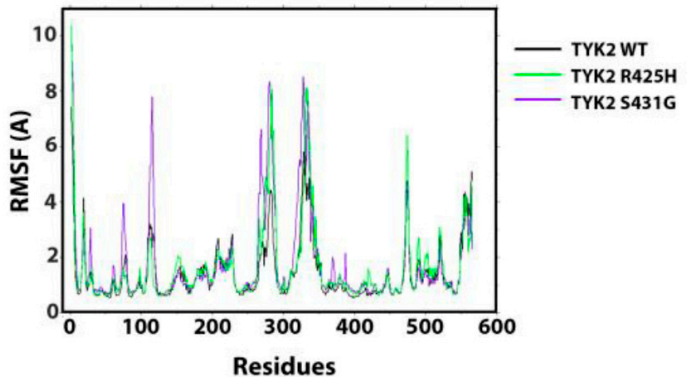

(C)

Figure 5. Interaction of four-point-one, ezrin, radixin, moesin (FERM) and src-homology 2 (SH2) domains of TYK2 with IFNAR1- $\alpha / \beta$ receptor alpha chain (IFNAR1). (A) 3D representation of the interaction of TYK2 FERM and SH2 domains with IFNAR1 (ID PDB: 4PO6). FERM domain is represented by subdomains (F1, F2, and F3) in red, SH2 domain in blue, and IFNAR1 in yellow; the sites of TYK2 R425 and S431 are represented with spheres in the protein structure and are indicated with black arrows. (B) Structural models from 0 to $50 \mathrm{~ns}$ of molecular dynamics (MD) of the TYK2-IFNAR1 complex, using the WT, R425H and S431G mutants. (C) Root mean square deviation (RMSD) and root mean square fluctuation (RMSF) of the TYK2 WT-IFNAR1, the TYK2 R425H-IFNAR1, and TYK2 S431G-IFNAR1 complexes. RMSD as a function of time (left) and RMSF vs. residues (right).

For that purpose, the energy of the system was monitored as a function of time (Figure S4) establishing that from $10 \mathrm{~ns}$ it remains stable. The $50 \mathrm{~ns}$ structural models of MD of the complex showed that IFNAR1 remains bound to TYK2 WT, TYK2 R425H, and TYK2 S431G. The analysis of the MD trajectory (Figure 5C) showed a small difference in the RMSD between the WT and the two mutants, attributed mainly to the dynamics itself; likewise, the RMSF of both complexes overlap and discrepancies only appear in small regions (residues 286-311 and 346-365). The theoretical energy calculations are detailed (Table S3) and they gave a binding affinity $\left(\Delta \mathrm{G}_{\text {bind }}\right)$ of $-117.85,-122.81$, and -126.49 for the complexes TYK2 WT-IFNAR1, TYK2 R425H-IFNAR1, and TYK2 S431G-IFNAR1, respectively.

\subsection{TYK2 Expression Analysis in B-ALL Patients}

TYK2 function could also be affected by changes at the expression level. To test whether TYK2 expression was altered in B-ALL patients, we performed RT-qPCR in bone marrow samples of 88 B-ALL patients at diagnosis (67 paediatric, age ranging from 1 to 17 years, median 5, mean 6.9; 21 adults, ranging from 21 to 90, median 48, mean 49.9) compared to PBMCs of 105 healthy donors (seven umbilical cords and 98 adults with age ranging from 19 to 66 years (median 33, mean 35.1)) (Figure 6). TYK2 expression was significantly lower in patients $(p \leq 0.05)$ compared to that in healthy donors (Figure 6A). Twelve (13.64\%) of the B-ALL patients analysed showed TYK2 variants, while 33 $(37.5 \%)$ did not present any variant and 44 were not sequenced. Regarding the most frequent TYK2 variant (I648S) present in eight of the patients evaluated, it displayed quite a heterogeneous expression 
pattern. Surprisingly, the two patients bearing TYK2 R425H or S431G had a very low RNA expression level, whereas those with TYK2 R703W or R832W (variants located in the pseudokinase domain) showed high TYK2 expression (see coloured dots in Figure 6B). However, these few cases were not enough to establish an association between expression level and variant presence. There were significant differences in TYK2 expression in B-ALL between children under 18 years and adults $(p \leq 0.001)$ (Figure 6B), while no significant differences were found regarding genetics (WHO subgroups), sex or blast cell count (data not shown). To obtain better insight into the relationship between TYK2 expression and age, a correlation analysis was performed including controls and patients (Figure S5). The results indicated that TYK2 expression was associated with age in B-ALL patients $($ rho $(\rho)=-0.46 ; p<0.001)$ but not in healthy controls $(\rho=-0.16 ; p=0.140)$. However, the low number of paediatric control samples included in this study due to their low availability must be noted. Overall survival (OS) analysis (Figure S6) considering both TYK2 expression and age did not reach statistically significant differences $(p=0.822)$. As expected, in our cohort, adults had a 3.7-fold risk of early death compared to children $(95 \% \mathrm{CI}=1.56-8.77, p=0.003)$.

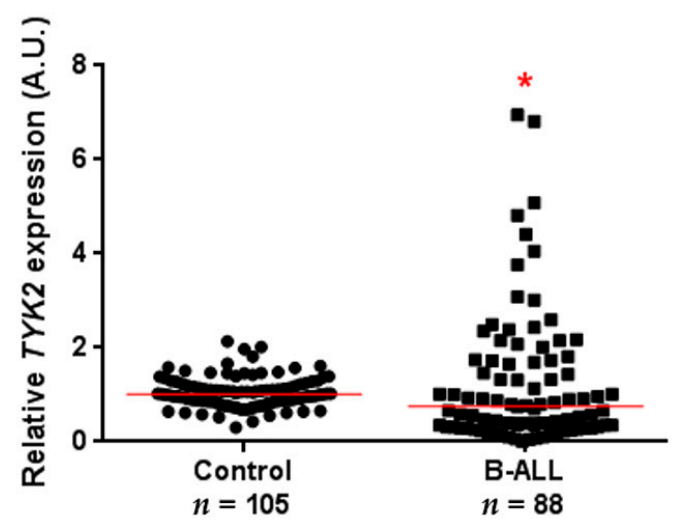

(A)

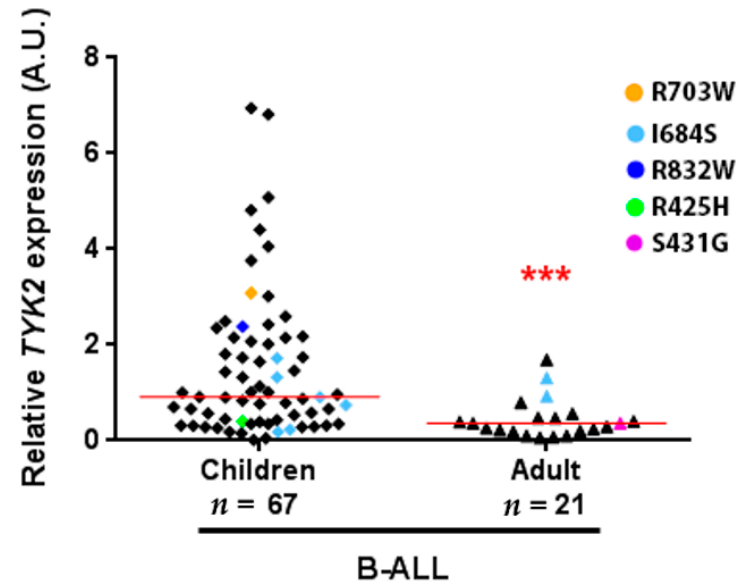

(B)

Figure 6. TYK2 expression in B-cell precursor acute lymphoblastic leukaemia (B-ALL) patients. qPCR was performed on cDNA obtained from $1 \mu \mathrm{g}$ of RNA isolated from the bone marrow of B-ALL patients and peripheral blood mononuclear cells (PBMCs) of healthy donors. For each sample, data were standardised against GAPDH expression. (A) Total B-ALL patients compared to healthy donors. Red line shows the median in each group (1.009 vs. 0.7594). (B) Age-related TYK2 expression in B-ALL patients. Children under 18 years compared to adults (median: 0.9147 vs. 0.3609). Patients with TYK2 variants are highlighted with different colours. ${ }^{*} p<0.05,{ }^{* * *} p \leq 0.001$.

\section{Discussion}

B-ALL is a heterogeneous malignancy with a broad spectrum of genetic alterations, although one third of B-ALL patients do not have molecular markers associated with the disease. The improvement of cytogenetic and genomic techniques and integration with NGS has enabled detailed characterisation of the genomic complexity of B-ALL. In previous studies it has been reported that a set of mutated gene exons are hot-spot regions for leukaemia (TP53, JAK2, PAX5, EBF1, LEF1, IL7Ra, and IKFZ) $[4,45]$. Within the JAK family, JAK2 gain-of-function mutations such as R683G/S have been associated with B-ALL $[4,46]$. Although the TYK2 gene is very polymorphic and more than 100 variants have been described in humans, $T Y K 2$ germline mutations have been recently described in two patients with a secondary B-ALL [19]. These TYK2 mutations (P760L and G761V) are located in two adjacent codons of the pseudokinase domain and have been proposed, based on in silico predictions, as activating mutations predisposing to the development of ALL. We did not find these mutations in our patient cohort. However, the inactivating cancer-associated germline SNP P1104A, described in independent tumour tissues and in AML [20,21,36], was found in two cases (3.22\%). Recently, homozygous P1104A 
has been described as a common monogenic aetiology factor of tuberculosis [35]. The susceptibility to infection is a hallmark of leukaemia [47], and it is associated with TYK2 deficiency in humans and mice [11,13-15]. TYK2 R703W detected in one of our patients has also been found in AML, and neither the impairment of TYK2 phosphorylation nor its effect on TYK2 protein expression was detected when transduced in TYK2-deficient cells [21]. In addition, the missense TYK2 I684S, described as producing a catalytically impaired kinase [25] and associated to protection against autoimmune diseases [48], was detected in eleven patients $(17.74 \%)$ of our sequenced cohort, matching the frequency reported for AML patients [21], which is threefold the frequency found in T-ALL samples [32]. There are some discrepancies related to the functional impact of the I684S substitution. While TYK2 deficient cells overexpressing this variant show catalytically impaired protein [21,25], HEK293 cells modified by CRISP-Cas9 to express it show no differences in TYK2 or STAT phosphorylation or in the expression of TYK2 protein with respect to parental cells [34].

The VAF for TYK2 variants detected in our patients suggests that they are heterozygous in blast cells. Unfortunately, our study was retrospective and other tissues were no longer available to determine whether they are also present in non-tumour cells. Interestingly, TYK2 R425H was previously found in the T-ALL cell line MOLT-16, but not in the T-ALL patients analysed, and was reported to be unable to transform murine pro-B Ba/F3 cells to IL-3 independent growth [32]. In this study, its capability to be phosphorylated and to activate STAT1/2, but not STAT3, and mediate target gene induction in response to IFN $\alpha$, is proven. Furthermore, even though the TYK2 R832W clone presented lower expression than the WT, the protein was able to be phosphorylated and induce earlier STAT target gene expression $(1 \mathrm{~h})$ when stimulated by IFN $\alpha$, similarly to the hyperactive V678F. Finally, TYK2 S431G is also functionally impaired in vitro, and cells carrying this mutation poorly induce STAT-target gene expression in response to IFN $\alpha$ stimulation, similarly to what is observed for the kinase-negative protein TYK2 K930R. Despite having the ATP binding site mutated, TYK2 K930R is still phosphorylated upon treatment with high doses of IFN $\alpha$ and allows some inducible gene expression due to JAK1-mediated cross-phosphorylation of conserved tyrosine residues within the activation loop of the kinase domain [25,49].

From a structural point of view, TYK2 R425H and S431G are located in the JH4 region within the FERM domain, which regulates the catalytic activity of the protein and has been implicated in the interaction with cytokine receptors [6]. It has been described that the 591 amino-terminal residues of TYK2 maintain the steady-state level of IFNAR1 protein in the cell [43] with the main interaction surface within JH7-6 regions. Additionally, the JH5-4-3 domains contribute to the in vivo assembly of TYK2 and IFNAR1 [50]. However, TYK2 residues 365-497 (JH4 region) transiently transfected in 293T cells did not show binding to the IFNAR1 cytoplasmic domain [51]. Accordingly, our dynamic structural analysis of TYK2-IFNAR1 interaction suggests that the mutation in residue 431 does not affect the interaction with IFNAR1. Interestingly, these TYK2 variants in the FERM and pseudokinase domains similarly impair kinase activity, suggesting that signalling through the JAK-STAT pathway is regulated on multiple levels, including intramolecular and intermolecular regulation [48].

Finally, it has been reported that TYK2 deficiency in mice increases the susceptibility to develop Abelson-induced B lymphoid leukaemia/lymphoma linked to a diminished cytotoxic capacity of Natural Killer (NK) and NKT cells as a consequence of decreased IFN- $\gamma$ production [16]. In addition, TYK2 is crucial for cytotoxic T-lymphocyte-mediated immune surveillance [52], therefore the low expression showed in B-ALL samples might unbalance this function. On the other hand, while TYK2 kinase activity is required for functional type I interferon responses in vivo [53], expression of the kinase-inactive mutant TYK2 K923E partially rescues NK cell-mediated anti-tumour response, thus supporting kinase-independent functions of TYK2 [54] that we cannot rule out for the variants analysed in the present study. At the same time, TYK2 plays an important role in B-cell development by mediating IFN $\alpha / \beta$-induced apoptosis of primary pro-B cells, which does not occur in TYK2-deficient mice [15,55]. To the best of our knowledge, this is the first analysis of TYK2 expression levels in immature human ALL-blasts, which is lower than in healthy PBMC. Further refinements to ascertain 
whether TYK2 expression is reduced in ALL cells as compared to that in normal precursor-B-cells would require samples not available at this point, and therefore this question remains to be elucidated. On the other hand, the described level of TYK2 expression in total PBMC (https:/www.proteinatlas.org/ ENSG00000105397-TYK2/blood) is lower compared to that in granulocytes, monocytes, or dendritic cells; similar to that in lymphocytes; and slightly higher than those of B-cell plasmablasts [56]. Further investigation should be performed to assess whether the low TYK2 expression found in ALL-blasts could favour the survival of leukaemic blasts in response to apoptotic signals and to define the role of these changes in B cell leukaemic disease.

\section{Conclusions}

In this study, we characterised a novel TYK2 variant (S431G), together with two rare polymorphisms ( $\mathrm{R} 425 \mathrm{H}$ and $\mathrm{R} 832 \mathrm{~W}$ ) found in B-ALL patients. These TYK2 variants presented differences in IFN signalling response and in STAT-target genes induction and none of them phosphorylated STAT3 in in vitro kinase assays. Molecular dynamic analysis of TYK2 variants located in the FERM domain (R425H and S431G) showed that the interaction with IFNAR1 was not affected by these point-mutations. Finally, TYK2 expression was lower in B-ALL patients compared to healthy controls. In summary, we provide evidence of naturally occurring catalytic loss-of-function TYK2 variants and reduced expression of TYK2 in B-ALL patients and propose that both mechanisms could contribute to facilitate tumour expansion.

Supplementary Materials: The following are available online at http://www.mdpi.com/2073-4425/11/12/1434/s1, Table S1: Sequences of primers used to amplify TYK2 in the NGS study, Table S2: Clinical data of patients with TYK2 non-synonymous variants, Table S3: Calculation of the theoretical energy components from the trajectories of molecular dynamics, Figure S1: Auto-phosphorylation activity of TYK2 variants and comparison of TYK2 expression in selected cell clones, Figure S2: Relative quantification of three replicates of TYK2 variant functional analysis, Figure S3: Molecular modelling of the superposition of FERM, SH2, and pseudokinase domains on TYK2 protein, Figure S4: Total energy time course of TYK2 WT-IFNAR1, TYK2 R425H-IFNAR, and TYK2 S431G-IFNAR1 complexes, Figure S5: Association between TYK2 expression and age, Figure S6: Overall survival of 88 B-ALL patients.

Author Contributions: Conceptualisation, E.T.-M., I.B.-M. and E.F.-R.; data curation, E.F.-R.; formal analysis, E.T.-M., I.B.-M., P.D.-W., F.M.-J., M.G.-A. and I.R.; funding acquisition, E.F.-R. and J.M.-L.; investigation, E.T.-M., I.B.-M., P.D.-W., F.M.-J., D.C.-A., M.G.-A. and I.R.; methodology, E.T.-M., I.B.-M., P.D.-W., F.M.-J., D.C.-A., M.G.-A. and I.R.; resources, M.C., C.D.-d.-H., E.B., M.R.-O., B.A., Á.F. and J.M.-L.; supervision, E.F.-R.; validation, E.T.-M., I.B.-M., P.D.-W., D.C.-A. and M.G.-A.; writing-original draft, E.T.-M., I.B.-M., P.D.-W. and E.F.-R.; writing-review and editing, E.F.-R., P.D.-W. and M.G.-A. All authors have read and agreed to the published version of the manuscript.

Funding: This study was supported by the Instituto de Salud Carlos III from the Spanish Ministry of Science, Innovation, and Universities, and the European Regional Development Fund (ISCIII-FEDER) “A way to achieve Europe", grants PI15/00032 and PI19/00096 to E.F.-R. and the Spanish Cancer Network (RD12/0036/0061 to J.M.). E.T.-M. was supported by a postdoctoral fellowship (329135) from The Mexican National Council for Science and Technology CONACYT (México) and I.B.-M. and P.D.-W. by PI15/0032 and PI19/00096 grants, respectively.

Acknowledgments: We thank the biological material and initial advice provided by S. Pellegrini (Institute Pasteur, Paris, France), M. Sala-Valdés and S. Barrio (University Hospital 12 Octubre, Madrid, Spain) for their initial work in NGS, N.B. Martín-Cófreces (IIS-IP, UAM) for helpful discussions, D. Ochoa (IIS-IP) for providing resources, L. Vega (IIS-IP) for help with statistical analysis, M. Gómez (IIS-IP) for critical reading and editing of the manuscript and the Fundación de Investigación Biomédica (FIB) administrative staff for support.

Conflicts of Interest: The authors declare no conflict of interest. The funders had no role in the design of the study; in the collection, analyses, or interpretation of data; in the writing of the manuscript; or in the decision to publish the results.

\section{References}

1. Liu, Y.F.; Wang, B.Y.; Zhang, W.N.; Huang, J.Y.; Li, B.S.; Zhang, M.; Jiang, L.; Li, J.F.; Wang, M.J.; Dai, Y.J.; et al. Genomic profiling of adult and pediatric B-cell acute lymphoblastic leukemia. EBioMedicine 2016, 8, $173-183$. [CrossRef] 
2. Iacobucci, I.; Mullighan, C.G. Genetic basis of acutfe lymphoblastic leukemia. J. Clin. Oncol. 2017, 35, 975-983. [CrossRef]

3. Bhojwani, D.; Yang, J.J.; Pui, C.H. Biology of childhood acute lymphoblastic leukemia. Pediatr. Clin. N. Am. 2015, 62, 47-60. [CrossRef]

4. Mullighan, C.G.; Zhang, J.; Harvey, R.C.; Collins-Underwood, J.R.; Schulman, B.A.; Phillips, L.A.; Tasian, S.K.; Loh, M.L.; Su, X.; Liu, W.; et al. JAK mutations in high-risk childhood acute lymphoblastic leukemia. Proc. Natl. Acad. Sci. USA 2009, 106, 9414-9418. [CrossRef] [PubMed]

5. Forero-Castro, M.; Robledo, C.; Benito, R.; Bodega-Mayor, I.; Rapado, I.; Hernandez-Sanchez, M.; Abaigar, M.; Maria Hernandez-Sanchez, J.; Quijada-Alamo, M.; Maria Sanchez-Pina, J.; et al. Mutations in TP53 and JAK2 are independent prognostic biomarkers in B-cell precursor acute lymphoblastic leukaemia. Br. J. Cancer 2017, 117, 256-265. [CrossRef] [PubMed]

6. Ghoreschi, K.; Laurence, A.; O'Shea, J.J. Janus kinases in immune cell signaling. Immunol. Rev. 2009, 228, $273-287$. [CrossRef] [PubMed]

7. Velazquez, L.; Fellous, M.; Stark, G.R.; Pellegrini, S. A protein tyrosine kinase in the interferon $\alpha / \beta$ signaling pathway. Cell 1992, 70, 313-322. [CrossRef]

8. Yeh, T.C.; Dondi, E.; Uze, G.; Pellegrini, S. A dual role for the kinase-like domain of the tyrosine kinase Tyk2 in interferon- $\alpha$ signaling. Proc. Natl. Acad. Sci. USA 2000, 97, 8991-8996. [CrossRef]

9. Strobl, B.; Stoiber, D.; Sexl, V.; Mueller, M. Tyrosine kinase 2 (TYK2) in cytokine signalling and host immunity. Front. Biosci. 2011, 16, 3214-3232. [CrossRef]

10. Stark, G.R.; Darnell, J.E., Jr. The JAK-STAT pathway at twenty. Immunity 2012, 36, 503-514. [CrossRef]

11. Kreins, A.Y.; Ciancanelli, M.J.; Okada, S.; Kong, X.F.; Ramirez-Alejo, N.; Kilic, S.S.; El Baghdadi, J.; Nonoyama, S.; Mahdaviani, S.A.; Ailal, F.; et al. Human TYK2 deficiency: Mycobacterial and viral infections without hyper-IgE syndrome. J. Exp. Med. 2015, 212, 1641-1662. [CrossRef] [PubMed]

12. Kilic, S.S.; Hacimustafaoglu, M.; Boisson-Dupuis, S.; Kreins, A.Y.; Grant, A.V.; Abel, L.; Casanova, J.L. A patient with tyrosine kinase 2 deficiency without hyper-IgE syndrome. J. Pediatr. 2012, 160, 1055-1057. [CrossRef] [PubMed]

13. Minegishi, Y.; Saito, M.; Morio, T.; Watanabe, K.; Agematsu, K.; Tsuchiya, S.; Takada, H.; Hara, T.; Kawamura, N.; Ariga, T.; et al. Human tyrosine kinase 2 deficiency reveals its requisite roles in multiple cytokine signals involved in innate and acquired immunity. Immunity 2006, 25, 745-755. [CrossRef] [PubMed]

14. Karaghiosoff, M.; Neubauer, H.; Lassnig, C.; Kovarik, P.; Schindler, H.; Pircher, H.; McCoy, B.; Bogdan, C.; Decker, T.; Brem, G.; et al. Partial impairment of cytokine responses in Tyk2-deficient mice. Immunity 2000, 13, 549-560. [CrossRef]

15. Shimoda, K.; Kato, K.; Aoki, K.; Matsuda, T.; Miyamoto, A.; Shibamori, M.; Yamashita, M.; Numata, A.; Takase, K.; Kobayashi, S.; et al. Tyk2 plays a restricted role in IFN $\alpha$ signaling, although it is required for IL-12-mediated T cell function. Immunity 2000, 13, 561-571. [CrossRef]

16. Stoiber, D.; Kovacic, B.; Schuster, C.; Schellack, C.; Karaghiosoff, M.; Kreibich, R.; Weisz, E.; Artwohl, M.; Kleine, O.C.; Muller, M.; et al. TYK2 is a key regulator of the surveillance of B lymphoid tumors. J. Clin. Investig. 2004, 114, 1650-1658. [CrossRef]

17. Ubel, C.; Mousset, S.; Trufa, D.; Sirbu, H.; Finotto, S. Establishing the role of tyrosine kinase 2 in cancer. Oncoimmunology 2013, 2, e22840. [CrossRef]

18. Leitner, N.R.; Witalisz-Siepracka, A.; Strobl, B.; Muller, M. Tyrosine kinase 2-Surveillant of tumours and bona fide oncogene. Cytokine 2017, 89, 209-218. [CrossRef]

19. Waanders, E.; Scheijen, B.; Jongmans, M.C.; Venselaar, H.; van Reijmersdal, S.V.; van Dijk, A.H.; Pastorczak, A.; Weren, R.D.; van der Schoot, C.E.; van de Vorst, M.; et al. Germline activating TYK2 mutations in pediatric patients with two primary acute lymphoblastic leukemia occurrences. Leukemia 2017, 31, 821-828. [CrossRef]

20. Kaminker, J.S.; Zhang, Y.; Waugh, A.; Haverty, P.M.; Peters, B.; Sebisanovic, D.; Stinson, J.; Forrest, W.F.; Bazan, J.F.; Seshagiri, S.; et al. Distinguishing cancer-associated missense mutations from common polymorphisms. Cancer Res. 2007, 67, 465-473. [CrossRef]

21. Tomasson, M.H.; Xiang, Z.; Walgren, R.; Zhao, Y.; Kasai, Y.; Miner, T.; Ries, R.E.; Lubman, O.; Fremont, D.H.; McLellan, M.D.; et al. Somatic mutations and germline sequence variants in the expressed tyrosine kinase genes of patients with de novo acute myeloid leukemia. Blood 2008, 111, 4797-4808. [CrossRef] [PubMed] 
22. Koppikar, P.; Bhagwat, N.; Kilpivaara, O.; Manshouri, T.; Adli, M.; Hricik, T.; Liu, F.; Saunders, L.M.; Mullally, A.; Abdel-Wahab, O.; et al. Heterodimeric JAK-STAT activation as a mechanism of persistence to JAK2 inhibitor therapy. Nature 2012, 489, 155-159. [CrossRef] [PubMed]

23. Pui, C.H.; Evans, W.E. Acute lymphoblastic leukemia. N. Engl. J. Med. 1998, 339, 605-615. [CrossRef] [PubMed]

24. Pellegrini, S.; John, J.; Shearer, M.; Kerr, I.M.; Stark, G.R. Use of a selectable marker regulated by alpha interferon to obtain mutations in the signaling pathway. Mol. Cell Biol. 1989, 9, 4605-4612. [CrossRef] [PubMed]

25. Li, Z.; Gakovic, M.; Ragimbeau, J.; Eloranta, M.L.; Ronnblom, L.; Michel, F.; Pellegrini, S. Two rare disease-associated Tyk2 variants are catalytically impaired but signaling competent. J. Immunol. 2013, 190, 2335-2344. [CrossRef]

26. DeLano, W.L. Use of PYMOL as a communications tool for molecular science. Abstr. Pap. Am. Chem. Soc. 2004, 228, U313-U314.

27. Case, D.A.; Cheatham, T.E.; Darden, T.; Gohlke, H.; Luo, R.; Merz, K.M., Jr.; Onufriev, A.; Simmerling, C.; Wang, B.; Woods, R.J. The Amber biomolecular simulation programs. J. Comput. Chem. 2005, 26, 1668-1688. [CrossRef]

28. Case, D.A.; Berryman, J.; Betz, R.M.; Cerutti, D.S.; Cheatham, T.E., III; Onufriev, A.; Simmerling, C.; Izadi, S.; Roitberg, A.; Wu, X.; et al. AMBER 2015; University of California: San Francisco, CA, USA, 2015.

29. Salomon-Ferrer, R.; Gotz, A.W.; Poole, D.; Le Grand, S.; Walker, R.C. Routine microsecond molecular dynamics simulations with AMBER on GPUs. 2. Explicit solvent particle mesh ewald. J. Chem. Theory Comput. 2013, 9, 3878-3888. [CrossRef]

30. Roe, D.R.; Cheatham, T.E. PTRAJ and CPPTRAJ: Software for processing and analysis of molecular dynamics trajectory data. J. Chem. Theory Comput. 2013, 9, 3084-3095. [CrossRef]

31. Zhou, Z.; Madura, J.D. Relative free energy of binding and binding mode calculations of HIV-1 RT inhibitors based on dock-MM-PB/GS. Proteins 2004, 57, 493-503. [CrossRef]

32. Sanda, T.; Tyner, J.W.; Gutierrez, A.; Ngo, V.N.; Glover, J.; Chang, B.H.; Yost, A.; Ma, W.; Fleischman, A.G.; Zhou, W.; et al. TYK2-STAT1-BCL2 pathway dependence in T-cell acute lymphoblastic leukemia. Cancer Discov. 2013, 3, 564-577. [CrossRef]

33. Sigurdsson, S.; Nordmark, G.; Goring, H.H.; Lindroos, K.; Wiman, A.C.; Sturfelt, G.; Jonsen, A.; Rantapaa-Dahlqvist, S.; Moller, B.; Kere, J.; et al. Polymorphisms in the tyrosine kinase 2 and interferon regulatory factor 5 genes are associated with systemic lupus erythematosus. Am. J. Hum. Genet 2005, 76, 528-537. [CrossRef] [PubMed]

34. Dendrou, C.A.; Cortes, A.; Shipman, L.; Evans, H.G.; Attfield, K.E.; Jostins, L.; Barber, T.; Kaur, G.; Kuttikkatte, S.B.; Leach, O.A.; et al. Resolving TYK2 locus genotype-to-phenotype differences in autoimmunity. Sci. Transl. Med. 2016, 8, 363ra149. [CrossRef] [PubMed]

35. Boisson-Dupuis, S.; Ramirez-Alejo, N.; Li, Z.; Patin, E.; Rao, G.; Kerner, G.; Lim, C.K.; Krementsov, D.N.; Hernandez, N.; Ma, C.S.; et al. Tuberculosis and impaired IL-23-dependent IFN-gamma immunity in humans homozygous for a common TYK2 missense variant. Sci. Immunol. 2018, 3, eaau8714. [CrossRef] [PubMed]

36. Hirbe, A.C.; Kaushal, M.; Sharma, M.K.; Dahiya, S.; Pekmezci, M.; Perry, A.; Gutmann, D.H. Clinical genomic profiling identifies TYK2 mutation and overexpression in patients with neurofibromatosis type 1-associated malignant peripheral nerve sheath tumors. Cancer 2017, 123, 1194-1201. [CrossRef] [PubMed]

37. Diogo, D.; Bastarache, L.; Liao, K.P.; Graham, R.R.; Fulton, R.S.; Greenberg, J.D.; Eyre, S.; Bowes, J.; Cui, J.; Lee, A.; et al. TYK2 protein-coding variants protect against rheumatoid arthritis and autoimmunity, with no evidence of major pleiotropic effects on non-autoimmune complex traits. PLoS ONE 2015, 10, e0122271. [CrossRef] [PubMed]

38. Eyre, S.; Bowes, J.; Diogo, D.; Lee, A.; Barton, A.; Martin, P.; Zhernakova, A.; Stahl, E.; Viatte, S.; McAllister, K.; et al. High-density genetic mapping identifies new susceptibility loci for rheumatoid arthritis. Nat. Genet 2012, 44, 1336-1340. [CrossRef]

39. Gakovic, M.; Ragimbeau, J.; Francois, V.; Constantinescu, S.N.; Pellegrini, S. The Stat3-activating Tyk2 V678F mutant does not up-regulate signaling through the type I interferon receptor but confers ligand hypersensitivity to a homodimeric receptor. J. Biol. Chem. 2008, 283, 18522-18529. [CrossRef]

40. Alvarez, J.V.; Frank, D.A. Genome-wide analysis of STAT target genes: Elucidating the mechanism of STAT-mediated oncogenesis. Cancer Biol. Ther. 2004, 3, 1045-1050. [CrossRef] 
41. Hartman, S.E.; Bertone, P.; Nath, A.K.; Royce, T.E.; Gerstein, M.; Weissman, S.; Snyder, M. Global changes in STAT target selection and transcription regulation upon interferon treatments. Genes Dev. 2005, 19, 2953-2968. [CrossRef]

42. Basham, B.; Sathe, M.; Grein, J.; McClanahan, T.; D'Andrea, A.; Lees, E.; Rascle, A. In vivo identification of novel STAT5 target genes. Nucleic Acids Res. 2008, 36, 3802-3818. [CrossRef] [PubMed]

43. Gauzzi, M.C.; Barbieri, G.; Richter, M.F.; Uze, G.; Ling, L.; Fellous, M.; Pellegrini, S. The amino-terminal region of Tyk 2 sustains the level of interferon alpha receptor 1 , a component of the interferon $\alpha / \beta$ receptor. Proc. Natl. Acad. Sci. USA 1997, 94, 11839-11844. [CrossRef] [PubMed]

44. Wallweber, H.J.; Tam, C.; Franke, Y.; Starovasnik, M.A.; Lupardus, P.J. Structural basis of recognition of interferon- $\alpha$ receptor by tyrosine kinase 2. Nat. Struct Mol. Biol. 2014, 21, 443-448. [CrossRef] [PubMed]

45. Kuiper, R.P.; Schoenmakers, E.F.; van Reijmersdal, S.V.; Hehir-Kwa, J.Y.; van Kessel, A.G.; van Leeuwen, F.N.; Hoogerbrugge, P.M. High-resolution genomic profiling of childhood ALL reveals novel recurrent genetic lesions affecting pathways involved in lymphocyte differentiation and cell cycle progression. Leukemia 2007, 21, 1258-1266. [CrossRef]

46. Bercovich, D.; Ganmore, I.; Scott, L.M.; Wainreb, G.; Birger, Y.; Elimelech, A.; Shochat, C.; Cazzaniga, G.; Biondi, A.; Basso, G.; et al. Mutations of JAK2 in acute lymphoblastic leukaemias associated with Down's syndrome. Lancet 2008, 372, 1484-1492. [CrossRef]

47. Roman, E.; Simpson, J.; Ansell, P.; Kinsey, S.; Mitchell, C.D.; McKinney, P.A.; Birch, J.M.; Greaves, M.; Eden, T.; United Kingdom Childhood Cancer Study, I. Childhood acute lymphoblastic leukemia and infections in the first year of life: A report from the United Kingdom childhood cancer study. Am. J. Epidemiol. 2007, 165, 496-504. [CrossRef]

48. Hammaren, H.M.; Virtanen, A.T.; Raivola, J.; Silvennoinen, O. The regulation of JAKs in cytokine signaling and its breakdown in disease. Cytokine 2019, 118, 48-63. [CrossRef]

49. Gauzzi, M.C.; Velazquez, L.; McKendry, R.; Mogensen, K.E.; Fellous, M.; Pellegrini, S. Interferon- $\alpha$-dependent activation of Tyk2 requires phosphorylation of positive regulatory tyrosines by another kinase. J. Biol. Chem. 1996, 271, 20494-20500. [CrossRef]

50. Richter, M.F.; Dumenil, G.; Uze, G.; Fellous, M.; Pellegrini, S. Specific contribution of Tyk2 JH regions to the binding and the expression of the interferon $\alpha / \beta$ receptor component IFNAR1. J. Biol. Chem. 1998, 273, 24723-24729. [CrossRef]

51. Yan, H.; Piazza, F.; Krishnan, K.; Pine, R.; Krolewski, J.J. Definition of the interferon- $\alpha$ receptor-binding domain on the TYK2 kinase. J. Biol. Chem. 1998, 273, 4046-4051. [CrossRef]

52. Simma, O.; Zebedin, E.; Neugebauer, N.; Schellack, C.; Pilz, A.; Chang-Rodriguez, S.; Lingnau, K.; Weisz, E.; Putz, E.M.; Pickl, W.F.; et al. Identification of an indispensable role for tyrosine kinase 2 in CTL-mediated tumor surveillance. Cancer Res. 2009, 69, 203-211. [CrossRef] [PubMed]

53. Prchal-Murphy, M.; Semper, C.; Lassnig, C.; Wallner, B.; Gausterer, C.; Teppner-Klymiuk, I.; Kobolak, J.; Muller, S.; Kolbe, T.; Karaghiosoff, M.; et al. TYK2 kinase activity is required for functional type I interferon responses in vivo. PLoS ONE 2012, 7, e39141. [CrossRef] [PubMed]

54. Prchal-Murphy, M.; Witalisz-Siepracka, A.; Bednarik, K.T.; Putz, E.M.; Gotthardt, D.; Meissl, K.; Sexl, V.; Muller, M.; Strobl, B. In vivo tumor surveillance by NK cells requires TYK2 but not TYK2 kinase activity. Oncoimmunology 2015, 4, e1047579. [CrossRef] [PubMed]

55. Gamero, A.M.; Potla, R.; Wegrzyn, J.; Szelag, M.; Edling, A.E.; Shimoda, K.; Link, D.C.; Dulak, J.; Baker, D.P.; Tanabe, Y.; et al. Activation of Tyk2 and Stat 3 is required for the apoptotic actions of interferon- $\beta$ in primary pro-B cells. J. Biol. Chem. 2006, 281, 16238-16244. [CrossRef] [PubMed]

56. Uhlen, M.; Karlsson, M.J.; Zhong, W.; Tebani, A.; Pou, C.; Mikes, J.; Lakshmikanth, T.; Forsstrom, B.; Edfors, F.; Odeberg, J.; et al. A genome-wide transcriptomic analysis of protein-coding genes in human blood cells. Science 2019, 366, eaax9198. [CrossRef]

Publisher's Note: MDPI stays neutral with regard to jurisdictional claims in published maps and institutional affiliations. 